\title{
Use of dry-weight rank multipliers for desert vegetation
}

\author{
ROSEMARY MAZAIKA AND PAUL R. KRAUSMAN
}

\section{Abstract}

The dry-weight rank technique has been used to measure vegetation in various habitats but has not been evaluated in desert shrub habitats. We sampled browse, forb, and grass in the palo-verde (Cercidium microphylum [Torr.] Rose and Johnston)-saguaro (Carnegiea gigantea [Engelm.] Britt and Rose) mountain slope vegetation association in the Sonoran Desert to determine if rank multipliers derived by $t$ Mannetje and Haydock differ from mean dry weights from different ranks. Previously derived multipliers were similar to those derived for mountain slope habitat.

Key Words: Arizona, desert, dry-weight rank, rank multipliers

Authors are graduate research assistant and professor of wildlife ecology, School of Renewable Natural Resources, University of Arizona, Tucson, Arizona 85721.

Research was funded by the National Rifle Association, the Estes Company, Tucson, and the University of Arizona, Agricultural Experiment Station. Authors thank D.W. Despain and E.L. Smith for discussion and ideas regarding manuscript preparation.

preparation.
Researchers often require large sample sizes to reduce variance when measuring vegetation. Several field technicians are usually required to obtain an adequate sample size. The dry-weight rank double-sampling technique assigns ranks 1, 2, and 3 (representing high to low standing crop) to the 3 most abundant species or lifeforms in a quadrat and applies a series of rank multipliers ('t Mannetje and Haydock 1963, Jones and Hargreaves 1979) to calculate percent composition of each species or lifeform for an entire survey area. The dry-weight rank technique is recommended for determining species composition by weight because individual observers can apply ranks more consistently than percentage or weight estimates and correlation coefficients among observers can be improved by training (Friedel et al. 1988).

Reese et al. (1980) determined that dry-weight estimation was significantly affected by litter depth, and variance in species composition and foliage cover. The applicability of the dry-weight rank 
technique and sensitivity to variations in vegetation distribution have been tested in tall-grass prairie ('t Mannetje and Haydock 1963), sub-alpine vegetation (Reese et al. 1980), and arid range (Friedel et al. 1988) and grassland (D.W. Despain, Univ. Arizona, pers. commun.). Studies of vegetation in arid ranges present problems relative to distribution because plants have an irregular distribution and biomass can fluctuate in a short period of time (Friedel et al. 1988). Although Friedel et al. (1988) reported useful application of the dry-weight rank technique in arid rangeland, they only sampled sub-shrubs and grasses. We sampled browse, forbs, and grass in the palo-verde (Cercidium microphylum [Torr.] Rose and Johnston-saguaro (Carnegiea gigantea [Engelm.] Britt and Rose) mountain slope vegetation association in the Sonoran Desert scrub habitat and wanted to know if the technique was also useful for these lifeforms. Our objective was to determine if rank multipliers determined by ' $t$ Mannetje and Haydock (1963) differed significantly from those derived from mean quadrat yield, and to determine the applicability of the dry-weight rank technique in desert ecosystem.

\section{Study Area}

The study area was the palo-verde-saguaro mountain slope association in the Pusch Ridge Wilderness, Coronado National Forest, Arizona. Dominant vegetation included common mesquite (Prosopis glandulosa Torr.), catclaw acacia (Acacia greggii Gray.), palo-verde, Mormon tea (Ephedra spp.), desert hop bush (Dodonea viscosa Jacq.), turpentine bush (Haplopappus laricifolius Gray.), buckwheat (Eriogonum spp.), brittlebush (Encelia farinosa Gray.), agave (Agave schotti Engelm.), saguaro, side-oats grama (Bouteloua curtipendula (Michx.), cotton-top grass (Trichachne californica [Benth.] Chase.), and globe mallow (Sphaeralcea spp.) Krausman et al. 1979).

\section{Methods and Methods}

We sampled vegetation during spring, summer, fall, and winter during 1987-88. We used a comparative yield technique (Haydock and Shaw 1975) to estimate plant biomass and the dry-weight rank ('t Mannetje and Haydock 1963) double-sampling technique to estimate percent composition of browse, forbs, and grass for each plot sampled. The comparative yield technique is a method for estimating biomass in which the biomass of random quadrats are rated with respect to a set of reference quadrats preselected in the field to provide a scale that is available throughout the sampling (Haydock and Shaw 1975). We established a comparative yield scale of 1 to 5 and used methods of Haydock and Shaw (1975) each season to estimate pasture yield. We photographed and retained photographs of yield estimates ( 1 to 5) for reference during subsequent field visits.

The dry-weight rank scale ranged from 1 to 3 and we visually ranked lifeforms in each plot from "most" to "least abundant." We visually ranked and clipped $44,1.4-\mathrm{m}^{2}$ quadrats ( $N \leq 17$ / season) and hand separated vegetation by lifeform and associated rank. Sample size for dry-weight rank was based on calculations for adequate comparative yield estimation. Calculations were derived from the variance of comparative yield estimates and observer efficiency (Haydock and Shaw 1975; Mazaika, unpubl. data). We oven-dried vegetation for 48 hours at $70^{\circ} \mathrm{C}$ and weighed it to obtain total weight/plot and relative weights of ranks 1,2 , and 3 . All estimates were made by 1 observer to increase precision. We transformed percent data using arcsine transformation and verified the accuracy of dry-weight rank multipliers relative to plot yield using the Chi-square distribution. We further compared mean weight of ranks 1 through 3 to multipliers $(70,21,9)$ derived by 't Mannetje and Haydock (1963) using the Chi-square distribution.

\section{Results and Discussion}

We selected the data collected in winter as a representative data set to illustrate the use of dry-weight rank multipliers for desert vegetation. Mean production for the palo-verde-saguaro mountain slope was $456.13 \pm 117.95(\bar{X} \pm \mathrm{SE}) \mathrm{kg} / \mathrm{ha}$ during winter. Percent composition of lifeforms estimated by percent quadrat yield and percent composition estimated by unweighted multipliers were similar $\left(\chi^{2}=0.39,2 \mathrm{df}, \mathrm{P}=0.80\right)$. Further analysis required arcsine transformation of yield data for each rank 1 through 3 to derive multipliers based on plot yield. Chi-square analysis of the multipliers derived from the mean percent weight $(40.76,39.04$, $22.35)$ and unweighted $(42.21,38.33,21.75)$ multipliers were similar $\left(\chi^{2}=0.43,2 \mathrm{df}, \mathrm{P}=0.80\right)$. Jones and Hargreaves (1979) recommend a weighting factor for estimates of pasture yield in areas where there is a consistent relationship between dry matter yield and species rank order. However, our comparison of percent composition of lifeforms estimated by percent quadrat yield with percent composition estimated by weighted multipliers (Jones and Hargreaves 1979) were different $\left(\chi^{2}=12.41,2 \mathrm{df}, P<0.005\right)$. Desert vegetation may not require weighing factors.

A major criticism of the dry-weight rank technique is that it relies on application of a predetermined set of multipliers to pastures of different homogeneity and spatial distribution (Sandland et al. 1982). Jones and Hargreaves (1979) calculated weighted multipliers for use with a wide range of vegetation; however, recalculation of multipliers did not necessarily increase the accuracy of the method and negated the positive aspects of rank estimation for double sampling in the desert shrub vegetation association. Our concern was in the application versus the underlying theoretical bias described by Sandland et al. (1980). We applied dry-weight rank estimates simultaneously with comparative yield samples because of the consistent relationship between the 2 techniques (Jones and Hargreaves 1979). We examined the ranks of 3 predominant lifeforms to determine if previously derived multipliers were consistent across vegetation types. Our results suggest that these multipliers accurately represent the proportions for occurrence of lifeforms in desert scrub habitat.

Friedel et al. (1988) concluded that differences among individual estimates and resulting correlations were highly influenced by spatial distribution of vegetation. Techniques that rely on dryweight estimates must account for the relationship between plot yield, distribution, and species composition. The mean production of ranks 1 through 3 , that we measured during December, illustrate the preponderance of forbs (rank 1) and limited quantity of grass (rank 3) in each quadrat. In comparison to mean rank yield for forbs and grass, unweighted multipliers reduce the magnitude of variation inherent in the sample plots. The degree to which this correction will accurately estimate percent composition of various lifeforms in areas of highly variable vegetative cover and spatial distribution should be assessed. Further research across other vegetation associations comprising the Sonoran Desert scrub community (i.e., desert floor, foothills, precipitous mountain slope, non-precipitous mountain slope) (Krausman et al. 1976) should investigate biases inherent in variation and spatial distribution of desert vegetation that may limit the applicability of the dry-weight rank technique in arid ecosystems.

\section{Literature Cited}

Friedel, N.H., V.H. Chewing, and G.N. Bastin. 1988. The use of comparative yield and dry-weight rank techniques for monitoring arid rangelands. J. Range Manage. 41:430-435.

Friedel, N.H., and K. Shaw. 1987. Evaluation of methods for monitoring sparse vegetation in arid rangelands. I. Herbage. J. Environ. Manage. 25:297-308. 
Haydock, K.P., and N.H. Shaw. 1975. The comparative yield method for estimating dry matter yield of pasture. Australian J. Exp. Agr. and Anim. Husb. 15:663-670.

Jones, R.M., and J.N.G. Hargreaves. 1979. Improvements to the dryweight-rank method for measuring botanical composition. Grass and Forage Sci. 34:181-189.

Krausman, P.R., W.W. Shaw, and J.L. Stair. 1979. Bighorn sheep in the Pusch Ridge Wilderness, Arizona. Desert Bighorn Counc. Trans. 23:40-46.
Reese, G.A., R.L. Bayn, and N.E. West. 1980. Evaluation of doublesampling estimators of subalpine herbage production. J. Range Manage. 33:300-306.

Sandland, R.L., J.C. Alexander, and K.P. Haydock. 1982. A statistical assessment of the dry-weight-rank method of pasture sampling. Grass and Forage Sci. 37:263-272.

t Mannetje, L., and K.P. Haydock. 1963. The dry-weight rank method for the botanical analysis of pasture. J. Br. Grassland Soc. 18:268-275. 